\title{
Estimation of Cytokines Involved in Acute-Phase Wound Infection with Reference to Residence Time of Patients in Hospitals
}

\author{
Mohemid M. Al-Jebouri'1 , Balsam Yahya R. Al-Mahmood ${ }^{2}$ \\ ${ }^{1}$ Department of Microbiology, College of Medicine, University of Tikrit, Tikrit, Iraq \\ ${ }^{2}$ Department of Microbiology, College of Medicine, University of Mosul, Mosul, Iraq \\ Email: profaljebouri@yahoo.com
}

How to cite this paper: Al-Jebouri, M.M. and Al-Mahmood, B.Y.R. (2019) Estimation of Cytokines Involved in Acute-Phase Wound Infection with Reference to Residence Time of Patients in Hospitals. Modern Research in Inflammation, 8, 1-10. https://doi.org/10.4236/mri.2019.81001

Received: January 28, 2019

Accepted: February 25, 2019

Published: February 28, 2019

Copyright $\odot 2019$ by author(s) and Scientific Research Publishing Inc. This work is licensed under the Creative Commons Attribution International License (CC BY 4.0).

http://creativecommons.org/licenses/by/4.0/

\begin{abstract}
Background: Cytokines have a major role in mediating immunity as well as inflammation. The main proinflammatory cytokines are activated after injury and implicated in healing interleukin-1 (IL-1), interleukin-6 (IL-6) and tumor necrosis factor- $\alpha$ (TNF- $\alpha$ ). High levels of IL- 6 are recorded at initial inflammatory response and start decreasing down to eight day of wounding while TNF- $\alpha$ level remained static and IL- $1 \alpha$ levels showed a different pattern of change following injury and consequence of infection. Methodology: This study was conducted in Al-Kindy and Al-Wasity hospitals in Baghdad on 200 patients suffering from wounds. One hundred patients were with acute wounds infection and the other 100 patients wounded but without infection and considered as control. Interleukin- $1 \alpha$ (IL- $1 \alpha$ ), interleukin-TNF- $\alpha$ (TNFa) and interleukin-6 (IL-60) were determined utilizing ELISA kit sandwich methods (Elabscience, USA). Results: The present study revealed that the values of IL- $1 \alpha$, and TNF- $\alpha$ at 48 hours of hospitalization were 23.547 and $27.177 \mathrm{pg} / \mathrm{ml}$ among patients with infected wounds respectively, and 7.05 and $28.127 \mathrm{pg} / \mathrm{ml}$ among patients without wound infections respectively. While IL-6 showed a highest level at 96 hours of residence in hospital and the value was $183.43 \mathrm{pg} / \mathrm{ml}$ for patients with infected wounds, and the value of the same interleukin was $88.696 \mathrm{pg} / \mathrm{ml}$ at 72 hours of residence of patients without wound infections. Conclusions: Interleukin- $1 \alpha$ elevated after $24 \mathrm{hr}$ of infection and then decreased. Proinflammatory cytokines (IL-6) was detectable within $24 \mathrm{hr}$ of infection. The highest concentration of IL-6 was seen with mixed bacteria and followed by gram negative bacteria and this probably due to lipopolysaccharide secretion caused an increase of IL- 6 in blood circulation. Irregular changes were seen in TNF- $\alpha$ values with durations of patients stay in hospitals.
\end{abstract}




\section{Keywords}

Acute-Phase, Infection, Wounds, Cytokines, Hospital Stay, Patients, Iraq

\section{Introduction}

Wound infection is invasive with pathogen to a level that invokes local and systemic response of the host. Presence of pathogen causes delayed wound healing. Bacteria are the most important pathogens contaminated wound and cause infection [1]. Inflammatory phase as a first stage of wound healing used neutrophils, macrophage, and lymphocytes [2]. Activated leukocytes, fibroblast, and endothelial cells represent the early response of tissue injury and infection to produce pro-inflammatory cytokines [3]. Cytokines have a major role in mediating immunity as well as inflammation. The main proinflammatory cytokines activated after injury and implicated in healing are interleukin-1 (IL-1 $\alpha$ ), interleukin-6 (IL-6) and tumor necrosis factor- $\alpha$ (TNF- $\alpha$ ) [4]. High level on initial inflammatory response is seen with IL- 6 then it decreases down to eight day postinfection. TNF- $\alpha$ level remains static while IL- $1 \alpha$ shows a second peak of increasing on post infection six days later [5]. IL-1 is the first signal alerts surrounding cells to barrier damage and attracting neutrophils to the site of infection to remove bacteria and other pathogens [6]. TNF- $\alpha$ and IL- $1 \beta$ have significant influence on the site of injury in the acute inflammatory response such as activating fibroblast, endothelial and leukocytes. TNF- $\alpha$ causes aggregation and priming neutrophils lead to augmented response to mediators [7]. IL-6 is produced by neutrophils and monocytes which is important in initiating the healing response to be increased after wounding and persist in older wounds [8]. IL-6 has a proliferative effect on keratinocytes with chemoattractive to neutrophils [9], as well as play roles in regulation and synthesis of c-reactive protein [10]. The present study is an attempt to assess the values of selected cytokines suspected to be involved in acute inflammatory responses of the wounds at different times of hospital stay.

\section{Materials and Methods}

\subsection{Patients}

A cross-sectional study was performed at Al-Wasity and Al-Kindy hospitals of Baghdad, Iraq during the period from December 2017 to August 2018. The number of patients was 200; and the selection criteria were as follow: 100 patients were with infected wound and sign of inflammation (acute wounds infection) like surgical wounds, burn wounds, laceration, abrasions, cut and bites; and the other 100 patients were wounded but without infections and considered as control groups. Ethical clearance for the study was obtained from the Committee of Higher Studies in College of Medicine, University of Tikrit. 


\subsection{Estimation of Interleukins}

Five milliliters of blood was collected by vein puncture using disposable syringe. Blood samples were placed into plan tube for immunological tests. The blood tubes were left for 15 - 30 minutes at room temperature for blood clotting. Tubes were centrifuged for 5 minutes at $3000 \mathrm{rpm}$. The separated serum was kept at deep freeze $\left(-70^{\circ} \mathrm{C}\right.$ for further studies [11]. ELISA kits utilized the sandwichELISA principle (Elabscience, USA) for determination of IL- $1 \alpha$, TNF- $\alpha$ and IL-6 in the sera of patients at $48,72,96$ and 120 hours of stay at hospital.

\subsection{Statistical Analysis}

F-test utilizing ANOVA computer program was used for data analysis and the significance was considered at $\mathrm{P}$ value of less than 0.05 .

\section{Results}

It was found that the highest value of IL- $1 \alpha$ was almost $24 \mathrm{pg} / \mathrm{ml}$ at 48 hours of residence and the lowest value was $1.6 \mathrm{pg} / \mathrm{ml}$ recorded at 96 hours. The concentration of this interleukin was highly elevated again at 120 hours of hospitalization of patients with wound infections (Figure 1). The value of IL- $1 \alpha$ among patients without wound infection (control) was sharply decreased with time of residence in hospitals e.g. $7.05 \mathrm{pg} / \mathrm{ml}$ at 48 hours and $0.155 \mathrm{pg} / \mathrm{ml}$ at 96 hours of hospitalization i.e. the stay in hospital (Figure 2). The statistical analysis showed a significant difference between different values using F-test $(\mathrm{P}<0.05)$.

Figure 3 shows an irregular change in TNF- $\alpha$ values with durations of patients stay in hospitals, e.g. the mean value was $27.2 \mathrm{pg} / \mathrm{ml}$ at 48 hours and this value was sharply decreased after 96 hours of residence in hospital to become 8.1 $\mathrm{pg} / \mathrm{ml}$; the same interleukin concentration sharply elevated at 120 hours of stay to reach $26.8 \mathrm{ph} / \mathrm{ml}$. The serum concentration of the TNF- $\alpha$ of patients without wound infections (Figure 4) was almost $28 \mathrm{pg} / \mathrm{ml}$ at 48 hours and this value decreased at 72 and 96 hours of stay to become 16.4 and $20.2 \mathrm{pg} / \mathrm{ml}$ respectively. The statistical analysis of the data mentioned concerning TNF- $\alpha$ showed significant differences $(\mathrm{P}<0.05)$ using F-test.

The present study revealed that IL- 6 serum concentration of patients with wound infections was steadily increased to reach the highest value at 96 hours of hospital stay when the value was $183.4 \mathrm{pg} / \mathrm{ml}$. Then the IL- 6 amount in serum abruptly decreased at 120 hours of stay to be $51.8 \mathrm{pg} / \mathrm{ml}$ (Figure 5). Whereas the highest concentration of IL- 6 among patients without wound infection recorded at 72 hours of stay. The other values recorded at 48 and 96 hours of stay were relatively low (Figure 6). Statistically, data analysis showed significant differences between different values of this interleukin using F-test $(\mathrm{P}<0.05)$.

Figure 7 and Figure 8 clearly reveal the comparative effect of duration of stay of patients in hospitals. This effect was reversable with respect to interleukin- $1 \alpha$ and interleukin- 6 since the first decreased with stay and the second one increased anong patients with acute-wound infections (Figure 7). The statistical 
analysis of the data showed signicant differences and the $\mathrm{P}$ value was $<0.05$ using F-test. Interleukin-1 $\alpha$ and TNF- $\alpha$ almost decreased with time of stay of patients without wound infection (Figure 8 ) and the differences were statistically significant utilizing F-test $(\mathrm{P}$ value $<0.05)$.

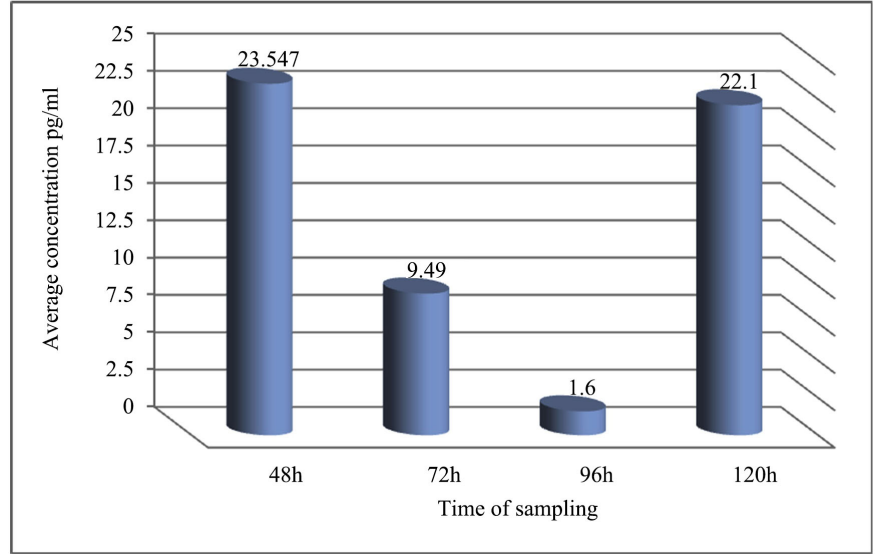

Figure 1. Values of IL-1 $\alpha$ from patients with acute-phase wounds infection at different times of stay at hospital.

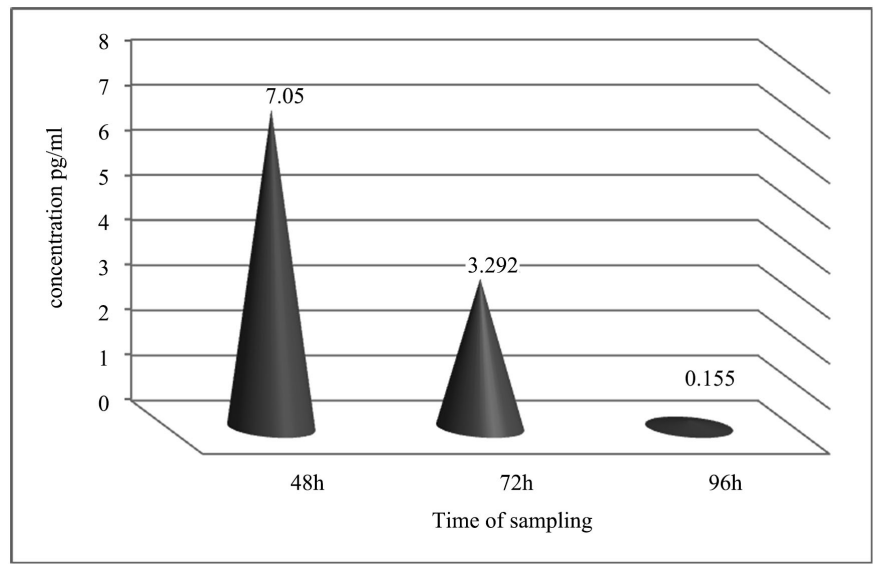

Figure 2. Serum values of IL- $1 \alpha$ from patients without wound infections at different times of stay at hospital.

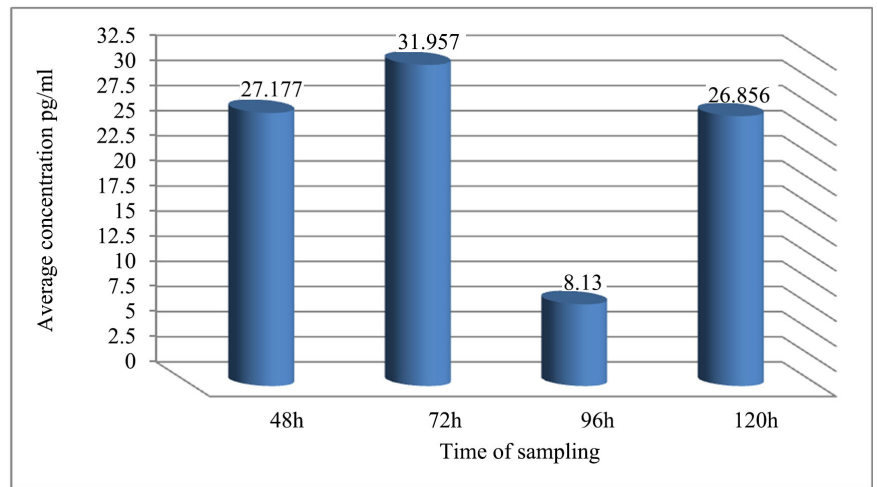

Figure 3. Values of TNF- $\alpha$ from patients with acute-phase wounds infection at different times of stay at hospital. 


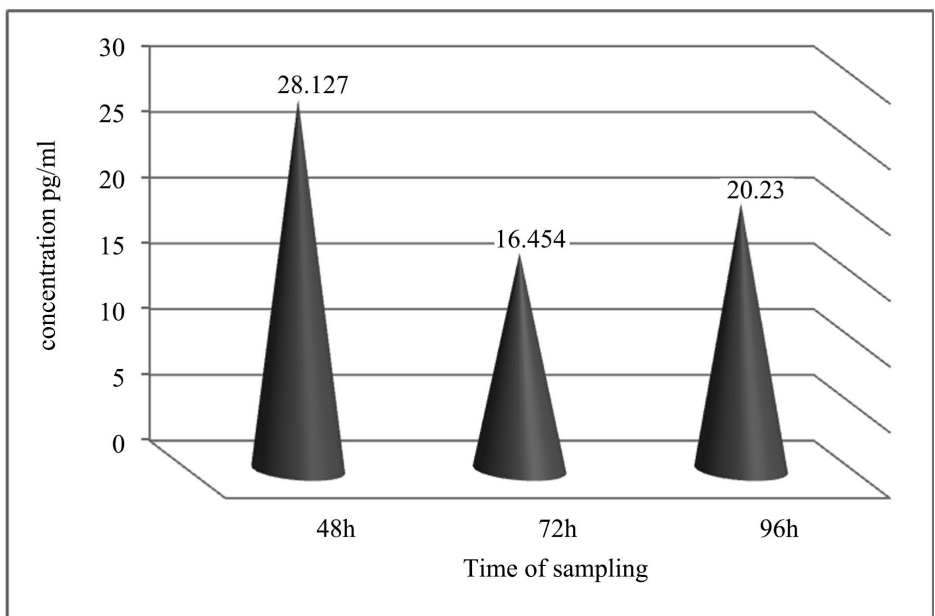

Figure 4. Values of TNF- $\alpha$ from patients without wound infections at different times of stay at hospital.

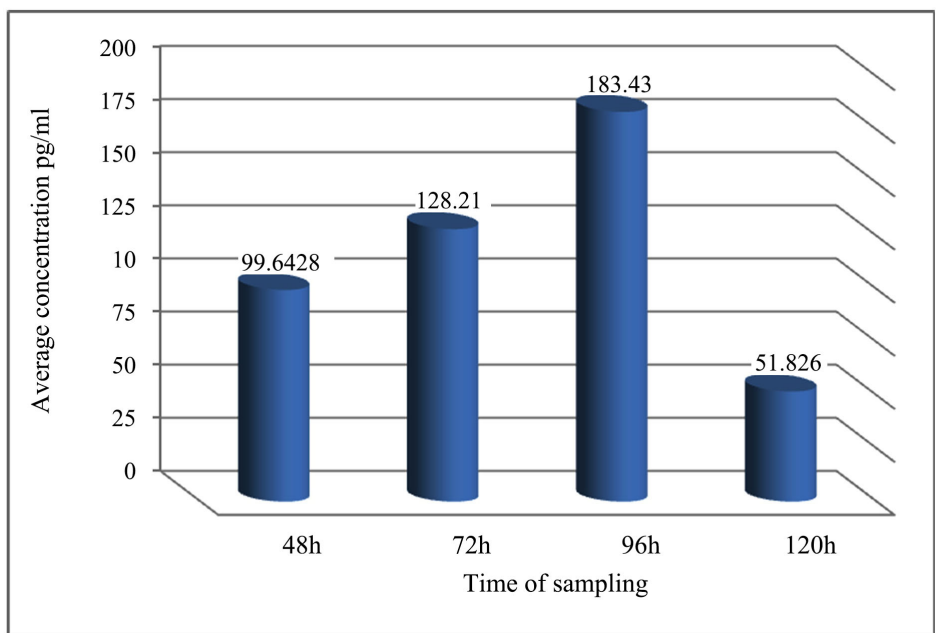

Figure 5. Values of IL-6 from patients with acute-phase wounds infection at different times of stay at hospital.

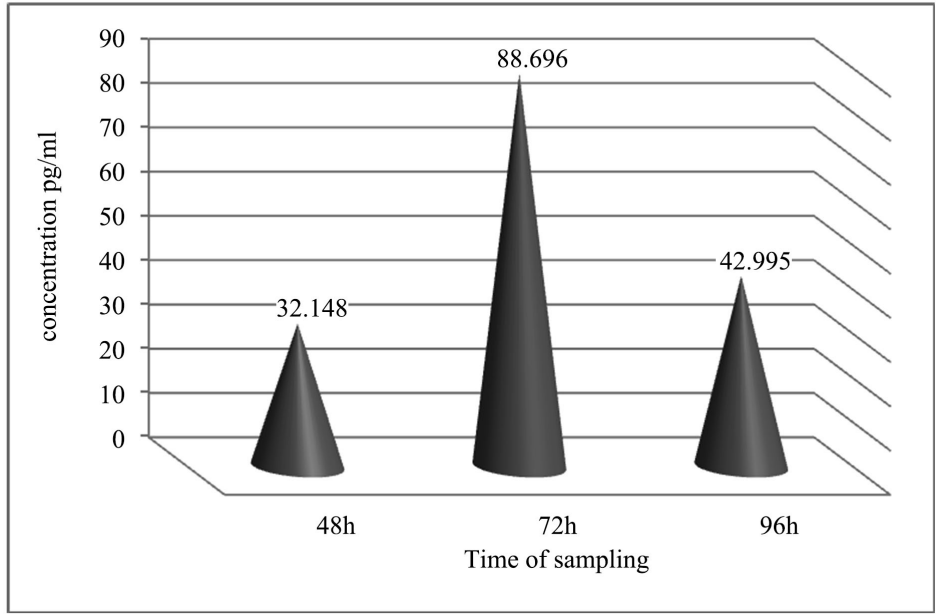

Figure 6. Values of IL-6 from patients without wound infections at different times of stay at hospital 


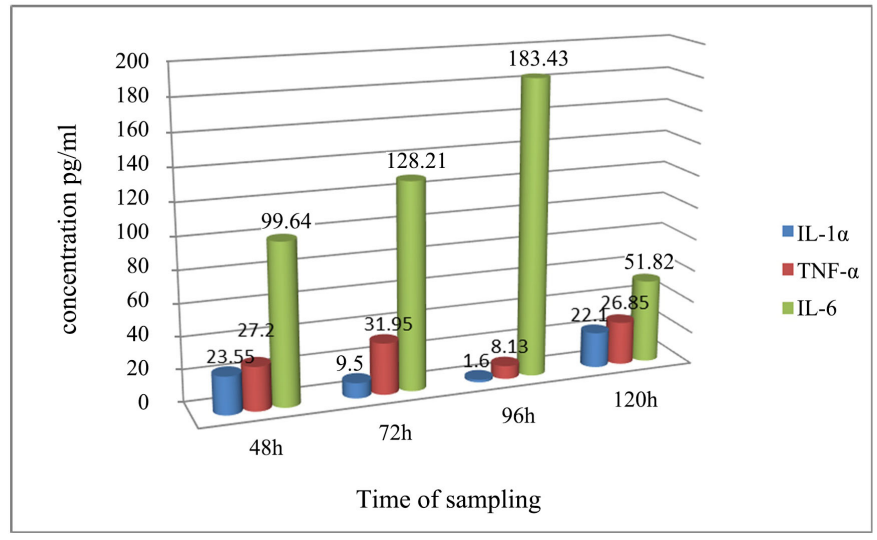

Figure 7. Comparative estimation of different interleukins values among patients with acute-phase of wound infection.

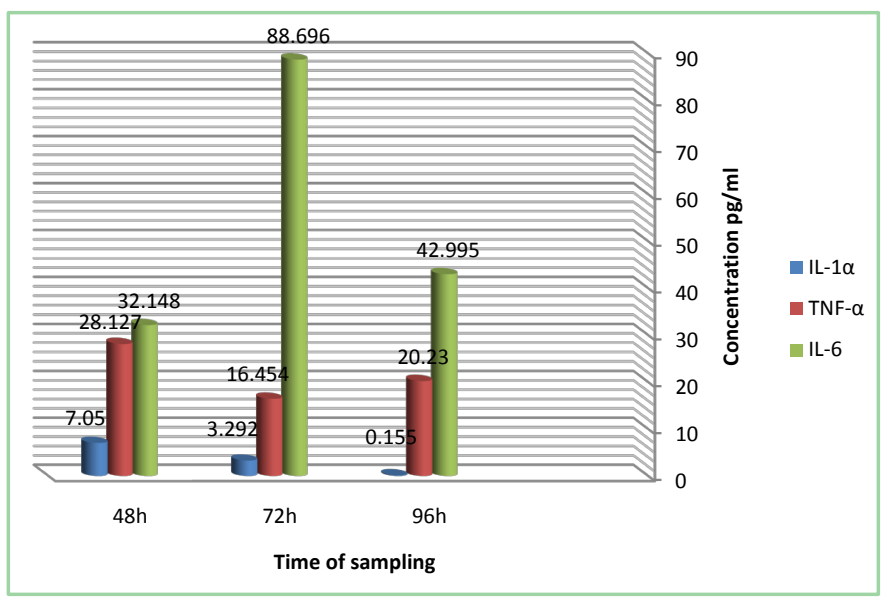

Figure 8. Comparative estimation of different interleukins values among patients without wound infection.

\section{Discussion}

Wound healing is usually completed within two weeks after injury but the tissue remodeling may take several months even up to two years. A delay in healing could be due to number of factors particularly infections [12]. The infection might spread throughout the body via blood stream and might cause systemic symptoms such as fever, chills, tachycardia and septicaemia [13]. However, according to present study, the serum concentrations of IL- $1 \alpha$, TNF- $\alpha$ and IL-6 were estimated at $48,72,96$, and $120 \mathrm{hrs}$ of patients stay at hospitals (Figures 1-6). However, it was found that the concentration of IL- $1 \alpha$ increased among patients with infected wounds particularly at $48 \mathrm{hrs}$ of hospitalization i.e. time of stay, and the mean value was $23.547 \mathrm{pg} / \mathrm{ml}$. Furthermore, the value of IL-1 $\alpha$ sharply decreased $(1.6 \mathrm{pg} / \mathrm{ml})$ at $96 \mathrm{~h}$ of stay at hospital while the concentration of the same interleukin in patients with no wound infection i.e. the control group was 7.05 at $48 \mathrm{hrs}$. IL- $1 \alpha$ values are highly related to the degree of tissue damage as well as to bacterial infection [14]. Comparatively, this pattern of change in IL- $1 \alpha$ values was almost similar to that obtained by Schaudinn and 
co-workers who showed keratinocytes express IL- $1 \alpha$ with immediate release in case of damage or infection. Schaudinn and co-workers found that IL-1 $\alpha$ increased at injury after $20 \mathrm{hrs}$ of infection which is a very useful phenomenon to discriminate distinctly between infected and uninfected wounds which indicating a response of skin cells to the infection by bacteria [14]. On the other hand, the early production of IL- $\alpha$ at $24-48 \mathrm{hrs}$ with its decrease at $96 \mathrm{hrs}(1.6 \mathrm{pg} / \mathrm{ml})$ was essential role of this interleukin in wound healing and this was almost similar to what was concluded by Divita and co-workers who showed proinflammatory cytokines concentration decreased significantly in postoperative period on the 4th day [15]. Moreover, it was noted that there was a slight difference in concentration of TNF- $\alpha$ between infected and noninfected wounds at $48 \mathrm{hrs}$ and the values were 27.17 and $28.127 \mathrm{pg} / \mathrm{ml}$ respectively. The result reported here was different from that obtained by Legler and co-workers who found more TNF- $\alpha$ elevation in case of infection which might play an important role in innate immunity and host defense against bacterial, fungal, and parasitic infections [16]. In the present study, TNF- $\alpha$ peak level was achieved at $72 \mathrm{hrs}$ and it was $31.957 \mathrm{pg} / \mathrm{ml}$ for the infected wound and the same conclusion was reported by Ritsu and co-workers who showed that TNF- $\alpha$ was detected in wound with peak level of $82 \mathrm{pg} / \mathrm{ml}$ on the third day of wound injury [17]. Furthermore, Mori and co-workers concluded a rapid variation in TNF- $\alpha$ concentration and this might be due to its short half-life (14 - 18 minutes) [18]. On the other hand, the elevated concentration of TNF- $\alpha$ in the control wounds at $96 \mathrm{hrs}(20.23 \mathrm{pg} / \mathrm{ml})$ might be due to other reasons like viral hepatitis or urinary tract infection which lead to an increased proportion of proinflammatory cytokine [19]. Pathophysiological condition of wounds and secretion of macrophages are primed to stimulate the downregulation or upregulation of proinflammatory cytokines. Abnormal levels of TNF- $\alpha$, IL- $1 \beta$ and IL- 6 contributed to the progress of tissue necrosis and complications such as excessive inflammatory response [20]. Moreover, the concentration of IL- 6 was detectable within $48 \mathrm{hrs}$ and the peak level was seen at $96 \mathrm{hrs}$ and the mean values of infected and noninfected wound were 183.43 and $88.69 \mathrm{pg} / \mathrm{ml}$ respectively. IL-6 value was decreased at $120 \mathrm{hrs}$ (Figure $5)$. The change pattern of IL- 6 reported in the present study was almost similar to that obtained by Agay and co-workers who showed that IL- 6 elevated on first day, and a second peak progressed from 3rd day to fifth day with concentration of $200 \mathrm{pg} / \mathrm{ml}$ at $96 \mathrm{hrs}$. Serum IL-6 levels remained significantly higher than control [21]. Moreover, the present result was almost similar to that obtained by Divita and colleagues who showed proinflammatory cytokine (IL-6) is detectable after 24 hours of wounding and then the concentration decreased significantly in postoperative period on the 4th day. This might be due to significant tissue damage with very high rate of bacterial contamination which showed elevation of leukocyte and neutrophil counts causing high level of IL-6 [15]. In contrast, the data concluded in the present study were different from that obtained by Schaudinn and co-workers who concluded a case of IL-6 with no traceable amount was found in any sample of infected and noninfected (control) at 12 
hours of residence in hospital and only the uninfected samples at $20 \mathrm{hrs}$ revealed a significant increase in IL-6 concentration with value of $9.5 \mathrm{pg} / \mathrm{ml}$ [16].

\section{Conclusion}

Interleukin- $1 \alpha$ (IL- $1 \alpha$ ) elevated after $24 \mathrm{hr}$ of infection and then decreased. Proinflammatory cytokines (IL-6) was detectable within $24 \mathrm{hr}$ of infection. The highest concentration of IL- 6 was seen with mixed bacteria and followed by gram negative bacteria and this might be due to lipopolysaccharide secretion caused an increase of IL- 6 in blood circulation. Irregular changes were seen in TNF- $\alpha$ values with durations of patients stay in hospitals. The present study showed that the interleukin- $1 \alpha$ was decreased with stay in hospital and interleukin-6 increased among patients with acute-wound infections.

\section{Ethical Approval}

Ethical clearance for the study was obtained from the Committee of Higher Studies in College of Medicine, University of Tikrit. The researcher did not in any way expose participants of the study to physical or psychological harm. Participation in the study was strictly voluntary with the informed consent of participants that guaranteed their right to privacy. All authors hereby declare that all experiments have been examined and approved by the appropriate ethics committee and have therefore been performed in accordance with the ethical standards laid down in the 1964 declaration of Helsinki.

\section{Limitations}

Single region data is not generalized. For this reason a survey of the whole area can reflect the whole region should be done.

\section{Conflicts of Interest}

The authors declare no conflicts of interest regarding the publication of this paper.

\section{References}

[1] White, R.J. (2009) Wound Infection-Associated Pain. Journal of Wound Care, 18, 245-249.

[2] Ramasastry, S.S. (2005) Acute Wounds. Clinical Plastic Surgery, 32, 195-208.

[3] Desborough, J.P. (2000) The Stress Response to Trauma and Surgery. British Journal of Anaesthesia, 85, 109-117. https://doi.org/10.1093/bja/85.1.109

[4] Frantz, S., Bauersachs, J. and Ertl, G. (2009) Post-Infarct Remodeling: Contribution of Wound Healing and Inflammation. Cardivascular-Research, 81, 474-481. https://doi.org/10.1093/cvr/cvn292

[5] Correa, S.G., Maccioni, M., Rivero, V.E., Iribarren, P., Sotomayor, C.E. and Riera, C.M. (2007) Cytokines and the Immune-Neuroendocrine Network: What Did We Learn from Infection and Autoimmunity? Cytokine Growth Factor Review, 18, 125-134. 
[6] Hantash, B.M., Zhao, L., Knowles, J.A. and Lorenz, H.P. (2008) Adult and Fetal Wound Healing. Front Bioscience, 13, 51-61. https://doi.org/10.2741/2559

[7] Staros, E.B. (2005) Innate Immunity: New Approaches to Understanding Its Clinical Significance. American Journal of Clinical Patholology, 123, 305-312. https://doi.org/10.1309/N0C70VCU3EHL57WK

[8] Grellner, W., Georg, T. and Wilske, J. (2000) Quantitative Analysis of Pro-Inflammatory Cytokines (IL-beta, IL-6, TNF-alpha) in Human Skin Wounds. Forensic Science International, 113, 254-264.

[9] Barrientos, S., Stojadinovic, O., Golinko, M.S., Brem, H. and Tomic-Canic, M. (2008) Growth Factors and Cytokines in Wound Healing. Wound Repair and Regeneration, 16, 585-601. https://doi.org/10.1111/j.1524-475X.2008.00410.x

[10] Pepys, M.B. and Hirschfield, G.M. (2003) C-Reactive Protein: A Critical Update. Journal of Clinical Investigation, 111, 1805-1812. https://doi.org/10.1172/JCI200318921

[11] Kamlage, B., Neuber, S., Bethan, B., Maldonado, S.G., Wagner-Golbs, A., Peter, E. and Schatz, P. (2018) Impact of Prolonged Blood Incubation and Extended Serum at Room Temperature on Human Serum Metabolome. Journal of Metabolites, 8, $1-13$.

[12] Scales, B. and Huffnagle, G. (2013) The Microbime in Wound Repair and Tissue Fibrosis. Journal of Patholology, 229, 323-331.

[13] Serra, M.B., Barroso, W.A., Silva, N.N.D., Silva, S.D.N., Borges, A.C.R., Abreu, I.C. and Borges, M.O.D.R. (2017) From Inflammation to Current and Alternative Therapies Involved in Wound Healing. International Journal of Inflammation, 2017, Article ID: 3406215. https://doi.org/10.1155/2017/3406215

[14] Schaudinn, C., Dittmann, C., Jurisch, J., Laue, M., Günday-Türeli, N., Blume-Peytavi, U., Vogt, A. and Rancan, F. (2017) Development, Standardization and Testing of a Bacterial Wound Infection Model Based on EX Vivo Human Skin. PLoS ONE, 12, 186-196. https://doi.org/10.1371/journal.pone.0186946

[15] Divita, G., Patti, R., Vetri, G., Macchiarella, B., D’Agostino, P., Caruso, G., Ferlazzo, V., Arcoleo, F., Sammartano, S., Angileri, M. and Cillari, E. (2005) Production of Cytokines at the Operation Site. Giornale di Chirurgia, 26, 241-245.

[16] Legler, D.F., Micheau, O., Doucey, M.A., Tschopp, J. and Baron, C. (2003) Recruitment of TNF Receptor 1 to Lipid Rafts Is Essential for TNF- $\alpha$ Mediated NF- $\kappa$ B Activation. Immunity, 18, 655-664. https://doi.org/10.1016/S1074-7613(03)00092-X

[17] Ritsu, M., Kawakami, K., Kanno, E., Tanno, H., Ishii, K., Imai, Y., Maruyama, R. and Tachi, M. (2017) Critical Role of Tumor Necrosis Factor- $\alpha$ in the Early Process of Wound Healing in Skin. Journal of Dermatology and Dermatologic Surgery, 21, 14-19. https://doi.org/10.1016/j.jdds.2016.09.001

[18] Mori, R., Kondo, T., Ohshima, T., Ishida, Y. and Mukaida, N. (2002) Accelerated Wound Healing in Tumor Necrosis Factor Receptor p55-Deficient Mice with Reduced Leukocyte Infiltration. The FASEB Journal, 16, 963-974. https://doi.org/10.1096/fj.01-0776com

[19] Stacey, A.R., Norris, P.J., Qin, L., Haygreen, E.A., Taylor, E., Heitman, J., Lebedeva, M., DeCamp, A., Li, D., Grove, D., Self, S.G. and Borrow, P. (2009) Induction of a Striking Systemic Cytokine Cascade prior to Peak Viremia in Acute Human Immunodeficiency Virus Type 1 Infection, in Contrast to More Modest and Delayed Responses in Acute Hepatitis B and C Virus Infections. Journal of Virology, 83, 3733-3719. https://doi.org/10.1128/JVI.01844-08

[20] Liu, L., Li, X., Yang, J., Chai, J., Yu, Y., Duan, H., Song, H., Feng, R., Wang, T., Yin, 
H., Hu, Q., Wang, S. and Du, J. (2015) Comparison of Systemic Inflammation Response and Vital Organ Damage Induced by Severe Burns in Different Area. International Journal of Clinical and Experimental Pathology, 8, 6367-6376.

[21] Agay, D., Andriollo-Sanchez, M., Claeyssen, R., Touvard, L., Denis, J., Roussel, A.M. and Chancerelle, Y. (2008) Interleukin-6, TNF- $\alpha$ and Interleukine-1 Beta Levels in Blood and Tissue in Severely Burned Rats. European Cytokine Network, 19, $1-7$. 